\title{
Padronização da técnica de nanopartícula de ouro não modificada (AuNPs) para detecção de Actinobacillus pleuropneumoniae em pulmões de suínos ${ }^{1}$
}

\author{
Laila Natasha S. Brandão², Letícia C. Pitchenin², Fernanda H. Maruyama ${ }^{3}$, Cristiane \\ S. Chitarra ${ }^{2}$, Givago F.R. da Silva ${ }^{2}$, Cátia Klein ${ }^{4}$, Luciano Nakazato ${ }^{5}$ e Valéria Dutra ${ }^{5 *}$
}

\begin{abstract}
Brandão L.N.S., Pitchenin L.C., Maruyama F.H., Chitarra C.S., Silva G.F.R., Klein C., Nakazato L. \& Dutra V. 2014. [Standardization of unmodified gold nanoparticle (AuNPs) for detection of Actinobacillus pleuropneumoniae in swine lungs.] Padronização da técnica de nanopartícula de ouro não modificada (AuNPs) para detecção de Actinobacillus pleuropneumoniae em pulmões de suínos. Pesquisa Veterinária Brasileira 34(7):621-625. Laboratório de Microbiologia e Biologia Molecular, Universidade Federal do Mato Grosso, Av. Fernando Corrêa da Costa2367, Bairro Boa Esperança, Cuiabá, MT 78060900, Brazil. E-mail: valdutra@ufmt.br

Based on diagnostic tests for the detection of nucleic acids without amplification through the use of gold nanoparticles (AuNPs) have been described for various diseases. This study aimed to develop a technique of unmodified AuNPs to detect Actinobacillus pleuropneumoniae $(A p p)$. We used 70 lung samples from pigs, 17 with and 53 without characteristic lesions of pneumonia, to detect App. The primer used was based on ApxIV gene. The AuNPs test had a sensitivity of $93.8 \%$ and specificity of $84.6 \%$ when compared with PCR detection. The results showed good agreement between AuNPs and PCR testing, and the technique can be used as an alternative to conventional tests, since it is quick and easy, and does not require implementation infrastructure and skilled labor.
\end{abstract}

INDEX TERMS: Swine pneumonia, gold nanoparticle, AuNP, Actinobacillus pleuropneumoniae.

RESUMO.- Testes diagnósticos baseados na detecção de ácidos nucleicos sem amplificação prévia através da utilização de nanopartículas de ouro (AuNPs) têm sido descritos para várias enfermidades. Este trabalho teve como objetivo desenvolver uma técnica de AuNPs não modificada para detecção de Actinobacillus pleuropneumoniae (App). Utilizaram-se 70 amostras de pulmão de suínos, $17 \mathrm{sem}$ lesão e 53 com lesões características de pneumonia, ob-

\footnotetext{
${ }^{1}$ Recebido em 6 de junho de 2014.

Aceito para publicação em 7 de maio de 2014.

${ }^{2}$ Programa de Pós-Graduação em Ciências Veterinárias (PPGVET), Faculdade de Agronomia, Medicina Veterinária e Zootecnia (Famevz), Universidade Federal do Mato Grosso (UFMT), Av. Fernando Corrêa da Costa 2367, Bairro Boa Esperança, Cuiabá, MT 78060-900, Brasil.

${ }^{3}$ Bolsista de Iniciação Cientifica (PIBIC) do Laboratório de Microbiologia e Biologia Molecular, UFMT, Av. Fernando Corrêa da Costa 2367, Bairro Boa Esperança, Cuiabá, MT 78060-900.

${ }^{4}$ Embrapa Suínos e Aves, Cx. Postal 21, Concordia, SC 89700-000, Brasil.

${ }^{5}$ Docente do Departamento de Clínica Médica Veterinária, Laboratório de Microbiologia e Biologia Molecular, UFMT, Av. Fernando Corrêa da Costa 2367, Bairro Boa Esperança, Cuiabá, MT 78060-900. *Autor para correspondência: valdutra@ufmt.br
}

jetivando a detecção de App. 0 oligonucleotídeo utilizado foi baseado no gene ApxIV. 0 teste de AuNPs apresentou sensibilidade de $93,8 \%$ e especificidade de $84,6 \%$ quando comparado com a detecção pela PCR. Os resultados mostraram boa concordância entre os testes de AuNPs e a PCR, sendo que a técnica pode ser utilizada como alternativa aos testes convencionais, já que é de fácil e rápida execução e não exige infraestrutura e mão de obra especializada.

TERMOS DE INDEXAÇ̃̃O: Pneumonia suína, nanopartícula de ouro, AuNP, Actinobacillus pleuropneumoniae.

\section{INTRODUÇÃO}

A produção de carne suína no Brasil é altamente tecnificada e com certificação sanitária. Propriedades pequenas, médias e integradas a grandes empresas são as formas mais comuns de criação. 0 rebanho brasileiro de suínos é o quarto rebanho mundial, atingindo 38,9 milhões de cabeças em 2011. A produção de carne suína está próxima a 3,4 milhões de toneladas/ano. 0 consumo per capita em 2011 chegou a 14,88 kg, um aumento de 11,42\% em relação ao 
ano de 2010 e o número de animais abatidos nos primeiros dois trimestres de 2013 foi de 17.911 cabeças segundo o Instituto Brasileiro de Geografia e Estatística (2013).

Dentre os complexos patológicos que afetam os suínos, as doenças respiratórias apresentam destaque, devido à frequência e intensidade com que atingem rebanhos (Rossi et al. 2013). São consideradas doenças multifatoriais, provocando significativas perdas econômicas, geralmente associadas à produção intensiva, a fatores ambientais e de manejo (Hansen et al. 2010, Opriessnig, Gimenez-Lirola \& Halbur 2011). 0 diagnóstico baseia-se no isolamento do agente a partir de lesões suspeitas e, principalmente, em testes sorológicos para estabelecimento de medidas de controle (Coelho et al. 2004, Xie et al. 2013).

A pleuropneumonia suína (PPS) causada pela bactéria Actinobacillus pleuropneumoniae (App), provoca doença clínica caracterizada por pneumonia com pleurisia fibrinosa, lesões pulmonares necrohemorrágicas, adesões pleurais fibrinóticas e, em casos severos, à morte (Bossé et al. 2002). O contágio geralmente ocorre após inalação de aerossóis ou contato direto, o microrganismo inalado coloniza o tecido pulmonar aderindo-se ao muco, proteínas e a células hospedeiras com posterior multiplicação no local (Chiers et al. 2010). 0 monitoramento do status da doença em rebanhos, o controle e a erradicação são de fundamental importância devido a características de contágio rápido deste agente, para impedir que animais portadores sejam introduzidos em rebanhos saudáveis (Tremblay et al. 2013).

Testes indiretos são muito utilizados (Machado et al. 2001, Shin et al. 2011, Eamens et al. 2012a,b, GimenezLirola et al. 2014),para detecção simultânea de anticorpos para toxinas com sensibilidade de $82,7 \%$ e especificidade de 100\% (Gimenez-Lirola et al. 2014). São descritos testes de ELISA monovalentes e polivalentes para sorotipos, com sensibilidade e especificidade variando de $88,3 \%$ a $96,6 \%$ (Machado et al. 2001). A importância de alta sensibilidade e especificidade em testes diagnósticos é fundamental para monitoramento dos rebanhos.

Várias técnicas moleculares têm sido empregadas nos últimos anos para a detecção de App (Schaller et al. 2001, Souza et al. 2008, Hricinova et al. 2010, Rossi et al. 2013). Métodos que detectam o Ácido Desoxirribonucléico (DNA), como a Reação em Cadeia da Polimerase (PCR) são altamente sensíveis e de importância para diagnóstico, principalmente para microrganismos de cultivo fastidioso.

No PCR para App os genes alvos geralmente selecionados para a técnica apresentam intrínseca relação com outras espécies, como Actinobacillus sp., A. equuli, A. lignieresii, e $A$. suis (Xiao et al. 2006). 0 gene específico omlA em diferentes grupos de $A p p$ se assemelha ao gene $A p x$, ambos utilizados para a identificação da espécie de $A p p$ (Klein et al. 2003). 0 gene ApxIVA é específico para App, não sendo compartilhado nas demais espécies da família Pasteurellaceae (Schaller et al. 2001). Apesar das técnicas moleculares proporcionarem resultados rápidos, necessitam de investimentos em equipamentos e infraestrutura laboratorial, sendo inviável a realização das mesmas a campo, que representa dificuldades como o envio de material em condições ideais muitas vezes inviabilizando o cultivo do agente, principalmente no caso das doenças respiratórias suínas.

Recentemente, métodos diagnósticos baseados em AuNPs tem sido utilizados para uma rápida e sensível detecção direta de microrganismos, entre eles: Mycobacterium sp. (Baptista et al. 2006, Liandris et al. 2009, Hussain et al. 2013), Escherichia coli, com detecção de 54 nanogramas (ng) de DNA não amplificado e com $100 \%$ de sensibilidade (Bakthavathsalam et al. 2012), RNA de vírus da dengue com detecção de $1 \times 10^{1}$ TCID50 unidade (Carter et al. 2013) e Leishmania sp. com valores de detecção de 11,5 ng à 50ng DNA e sensibilidade de 56\% à 92\% (Rosa et al. 2013, Andreadou et al. 2014).

0 presente trabalho objetivou a padronização da técnica de AuNPs para detecção de App, em amostras clínicas de suínos com pneumonia.

\section{MATERIAL E MÉTODOS}

Amostras. As amostras testadas foram provenientes do Laboratório de Microbiologia e Biologia Molecular Veterinária da Universidade Federal de Mato Grosso e foram coletadas entre os anos de 2010 a 2013 originárias de diferentes regiões do estado de Mato Grosso. Foram testadas 70 amostras de pulmões de suínos, sendo 53 com lesões macroscópicas características de pneumonia (consolidação pulmonar, deposição de fibrina na pleura, pleurite ou aderência) e 17 sem lesões macroscópicas de animais em fase de terminação e abate.

Os controles positivos para a padronização do teste foram DNAs extraídos de cultivos de App sorotipos 3 e 5, e de Haemophilus parasuis, cedidos pelo Centro Nacional de Suínos e Aves-Embrapa e Pasteurella multocida proveniente de cultura no Laboratório de Microbiologia Veterinária da Universidade Federal de Mato Grosso confirmada por PCR e sequenciamento para o gene kmt1. O DNA de Escherichia coli ATCC 35218 e água ultra-pura foram utilizados como controles negativos.

Extração de DNA e PCR. A extração de DNA genômico das amostras de pulmões foi realizada segundo Sambrook \& Russel (2004) utilizando-se fenol e clorofórmio, com mínimas modificações (não utilização de álcool isoamílico). A realização dos testes de PCR para os microrganismos foram executadas de acordo com Xiao et al. (2006) para App, Townsend et al. (2001) para P. multocida e Angen et al. (2007) para H. parasuis. Os oligonucleotídeos e tamanho dos amplicons encontram-se no Quadro 1. A qualidade e integridade do DNA e os produtos de amplificação foram analisados em eletroforese em gel agarose 1,0\%, corado com Gel Red ${ }^{\text {mu }}$ $\left(\right.$ Biotium $^{\circledR}$ ) a 100 Volts por centímetro e observados em ChemiDoc $^{\mathrm{TM}}$ XRS utilizando o software Image Lab ${ }^{\mathrm{TM}}$ Software. Como marcador de massa molecular utilizou-se o padrão de 100 pares de base (pb) de DNA Ladder ${ }^{\mathrm{rm}}$ (Fermentas ${ }^{\circledR}$ ).

Preparação de AuNPs. Seguiu-se o método de redução de citrato segundo descrito por Grabar et al. (1995) que torna as partículas negativamente carregadas. Um volume de $250 \mathrm{ml}$ de cloreto de ouro (HAuCl4ACl) a $1 \mathrm{Mm}$ foi levado à fervura sob agitação e posteriormente foi acrescido nitrato de sódio na concentração de $38,8 \mathrm{mM}$ e mantido por agitação continua durante 15 minutos (min). A solução estoque foi mantida a $4^{\circ} \mathrm{C}$ e a solução em uso se manteve estável por três meses a temperatura ambiente.

Teste de AuNP. A hibridização foi realizada conforme descrito por Bakthavathsalam, Rajendran \& Mohammed (2012), a desnaturação do DNA genômico, sem prévia amplificação através de PCR, ocorreu a $95^{\circ} \mathrm{C}$ por $3 \mathrm{~min}$ em solução contendo $1,25 \mathrm{M}$ de 
Quadro 1. Oligonucleotideos e genes alvos utilizados na PCR e tamanhos de amplicons

\begin{tabular}{|c|c|c|c|c|c|}
\hline Agente & Primer & Sequência & Gene alvo & $(\mathrm{pb})$ & Autores \\
\hline $\begin{array}{l}\text { Actinobacillus } \\
\text { pleuropneumoniae }\end{array}$ & apxIV F & ATACGGTTAATGGCGGTAATGG & apxIVA & 346 & (Xiao et al. 2006) \\
\hline Haemophilus & HP1F3 & TATCGRGAGATGAAAGAC & 16s rDNA & 1090 & (Angen et al. 2007) \\
\hline parasuis & $\begin{array}{l}\text { HP2F2 } \\
\text { Revx }\end{array}$ & $\begin{array}{l}\text { GTAATGTCTAAGGACTAG } \\
\text { CCTGGCTTCGTC }\end{array}$ & & & \\
\hline Pasteurella & $\begin{array}{l}\text { KMT1T7 } \\
\text { KMT1SP6 }\end{array}$ & ATCCGCTATTTACCCAGTGG & $k m t 1$ & 460 & Townsend et al. 2001) \\
\hline
\end{tabular}

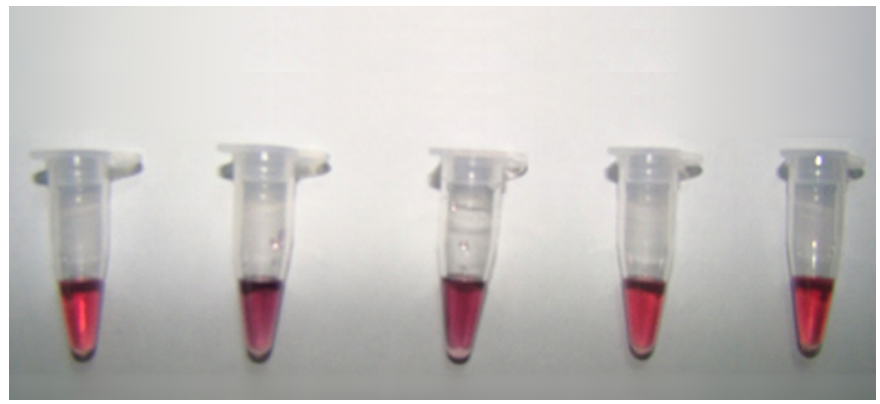

Fig.1. Limite de detecção de DNA de App pelo teste de AuNP's. Água, 649ng; 129,8ng; 25,6ng; 5,19ng, nesta ordem.

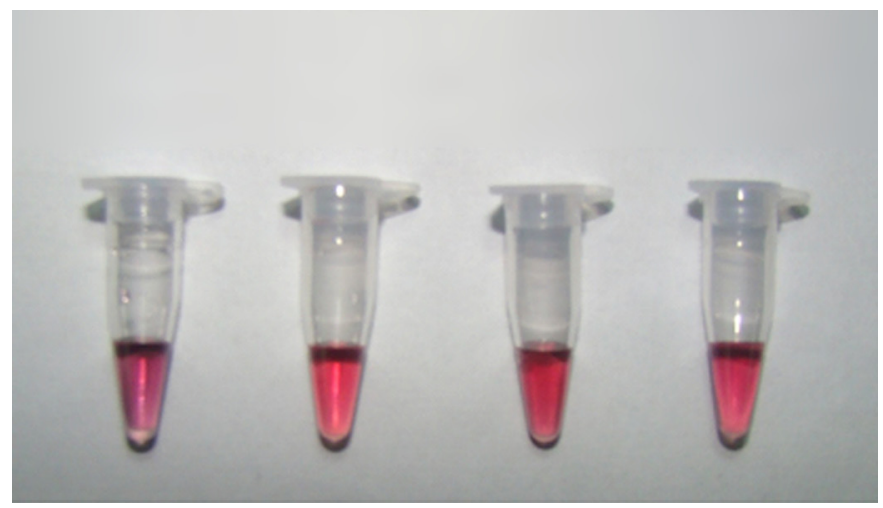

Fig.2. Especificidade do teste de AuNP com DNA de App, Haemophilus parasuis, Escherichia coli e Pasteuralla multocida, nesta ordem.

$\mathrm{NaCl}, 20 \mathrm{mM}$ de Tris, 70pMol do oligonucleotídeo apxIV R, que posteriormente foi resfriada para a $50^{\circ} \mathrm{C}$ por $2 \mathrm{~min}$ para permitir a hibridização com o iniciador. Imediatamente submeteu-se a reação ao resfriamento até que atingisse $4^{\circ} \mathrm{C}$ e adicionou-se $50 \mu \mathrm{l}$ do preparado de AuNPs.

As leituras das amostras foram realizadas de acordo com Hussain et al. (2013). 0 ponto de corte foi baseado na quantidade mínima de DNA capaz de induzir colorimetricamente (visualmente) as AuNPs de rosa (negativo) para roxo (positivo) e pela relação de suas respectivas leituras de densidade ótica a 520 e 600nm (OD). Os valores da relação de leitura acima de 0,5 foram considerados positivos e valores inferiores negativos (Hussain et al. 2013). A visualização macroscópica dos resultados foi possível 1 minuto após acréscimo da AuNPs. Os limites de detecção foram obtidos a partir de diluições seriadas dos DNAs de App sorotipos 3 e 5 e o controle negativo consistiu em $\mathrm{H}_{2} \mathrm{O}$ ultra pura. As imagens foram obtidas com câmera digital.

Análise estatística. A análise estatística foi realizada através do software R (R 2011) utilizando o pacote de dados Rcmdr (Fox 2005), para determinação da sensibilidade e especificidade da técnica e o teste Kappa para análise de concordância entre a técnica de PCR e as AuNPs.

\section{RESULTADOS}

O limite de detecção de DNA de amostras de App sorotipos 3 e 5 estão descritos no Quadro 4.0 menor nível de detecção foi de 129ng de DNA pelas avaliações macroscópica e relação $\mathrm{OD}_{520 / 600 \mathrm{~nm}}(0,55)$ (Fig.1). Não ocorreram alterações de coloração macroscopicamente e na leitura de OD para DNAs de outras bactérias como Pasteurella multocida, Haemophilus parasuis e Escherichia coli (Fig.2).

A detecção dos patógenos bacterianos respiratórios das amostras de pulmões pelo PCR está apresentada no Quadro 2. A presença de App foi detectada em 16 (22,85\%) das 70 amostras testadas. Destas, 8 (50\%) foram de pulmões com lesão e 8 (50\%) de pulmões sem lesão.

Na detecção de App pela técnica de AuNPs em pulmões, 23 amostras $(32,8 \%)$ foram positivas no teste, sendo 13 (24,5\%) com lesões e 11 (64,7\%) sem lesões (Quadro 3). Utilizando-se a técnica de PCR como padrão ouro obteve-se uma sensibilidade de 93,8\% e uma especificidade de $84,6 \%$ para AuNPs. A concordância entre PCR e AuNPs foi boa com índice Kappa de 0,684 (Quadro 5).

Quadro 2. Relação do total de amostras positivas e negativas para cada agente testado na PCR

\begin{tabular}{lccccc}
\hline Microrganismo & Amostras & \multicolumn{4}{c}{ PCR } \\
\cline { 3 - 6 } & & Negativo (\%) & Positivo & $(\%)$ \\
\hline \multirow{2}{*}{ Actinobacillus } & Com lesão & 45 & 84,91 & 8 & 15,09 \\
pleuropneumoniae & Sem lesão & 9 & 52,95 & 8 & 47,05 \\
& TOTAL & 54 & 77,15 & 16 & 22,85 \\
Haemophilus parasuis & Com lesão & 45 & 84,91 & 8 & 15,09 \\
& Sem lesão & 9 & 52,95 & 8 & 47,05 \\
& TOTAL & 54 & 77,15 & 16 & 22,85 \\
Pateurella multocida & Com lesão & 40 & 75,47 & 13 & 24,52 \\
& Sem lesão & 17 & 100 & 0 & 0 \\
& TOTAL & 57 & 81,42 & 13 & 18,57
\end{tabular}

Quadro 3. Número de amostras positivas e negativas nas AuNPs

\begin{tabular}{|c|c|c|c|c|c|c|}
\hline & \multicolumn{2}{|c|}{ Macroscopia } & \multicolumn{2}{|c|}{ O.D. } & \multicolumn{2}{|c|}{ PCR App } \\
\hline & Positivas & Negativas & Positivas & Negativas & Positiva & Negativa \\
\hline & $\mathrm{N}^{\circ}(\%)$ & $\mathrm{N}^{\circ}(\%)$ & $\mathrm{N}^{\circ}(\%)$ & $\mathrm{N}^{\circ}(\%)$ & $\mathrm{N}^{\circ}(\%)$ & $\mathrm{N}^{\circ}(\%)$ \\
\hline Com lesão & 1324,5 & 4075,5 & 1324,5 & 4075,5 & 815,1 & 4584,9 \\
\hline Sem lesão & 1058,8 & 741,2 & 1164,7 & 635,3 & 847,1 & 952,9 \\
\hline TOTAL & 2332,8 & 4767,2 & 2434,3 & 4665,7 & 1622,9 & 5477,1 \\
\hline
\end{tabular}

Quadro 4. Diluições seriadas de DNA de App

\begin{tabular}{lccc}
\hline Diluições & Concentração do DNA & Macroscopia & Relação da O.D. \\
\hline 1.Sorotipo 3 & 649 ng & Positivo & 0,605 \\
2.Sorotipo 3 & 129,8ng & Positivo & 0,558 \\
3.Sorotipo 3 & 25,6ng & Negativo & 0,447 \\
4.Sorotipo 3 & 5,192ng & Negativo & 0,415 \\
5.H20 & - & Negativo & 0,415
\end{tabular}


Quadro 5. Teste de sensibilidades especificidade das amostras

\begin{tabular}{lccc}
\hline Amostras & Sensibilidade & Especificidade & Kappa \\
\hline Com lesão & $87,5 \%$ & $86,7 \%$ & 0,590 \\
Sem lesão & $100 \%$ & $77,80 \%$ & 0,767 \\
TOTAL & $93,8 \%$ & $84,6 \%$ & 0,684
\end{tabular}

\section{DISCUSSÃO E CONCLUSÃO}

A nanociência tem tido inúmeras aplicações, soluções coloidais de metais podem ser facilmente preparadas e modificadas quimicamente, uma diversidade de cores pode ser observada relacionada às oscilações dos elétrons de condução em ressonância a luz incidente, desde que haja elétrons livres de condução (Melo Jr et al. 2012). A técnica de AuNPs tem sido utilizada para diagnóstico de Mycobaterium tuberculosis (Hussain et al. 2013), câncer de bexiga (Nossier et al. 2014), Leishmania sp. (Andreadou et al. 2014) e vírus da dengue (Carter et al. 2013). A detecção do DNA é baseada na adsorção das bases nitrogenadas aos oligonucleotídeos e a superfície das AuNPs. A agregação ocorre devido a presença de sal durante a hibridização, ocorrendo a atração e a agregação das AuNPs devido as cargas negativas que interagem com os cátions do sal. A coloração visual muda do vermelho par o azul na ausência do DNA alvo porque não ocorre a agregação (Hussain et al. 2013). A concentração, tamanho e temperatura de anelamento dos iniciadores utilizados, a concentração de sal e de nanopartículas são fatores que podem interferir nos resultados desta técnica.

O limite mínimo de detecção das AuNPs foi de 129,8ng de DNA genômico de App não amplificado, sendo o limite mínimo detectado por PCR com os mesmos oligonucleotídeos de acordo com Xiao et al. (2006) de 10 picogramas (pg) para DNA amplificado. Chan et al. (2014) obtiveram em amostras de PCR amplificado para genes de resistência àà meticilina em Staphylococcus aureus um valor para limite de detecção das AuNPs de 500ng e Hussain et al. (2013) valores de DNA não amplificado de 40ng, utilizando a técnica de nanopartículas de ouro sem adição do grupo tiol, uma pequena modificação nos oligonucleotídeos. A maior concentração de agentes no tecido estudado pode ser o motivo da maior sensibilidade encontrada neste estudo e em trabalhos, como o de Andreadou et al. (2014) que descrevem como valores mínimos de detecção de DNA de Leishmania sp. 11,5ng e Bakthavathsalam et al. (2012) que encontraram valor mínimo de detecção de 54ng de DNA de Escherichia coli. A funcionalização da AuNPs com oligonucleotídeos tiol modificados conduziu a primeira aplicação de AuNPs na detecção de ácidos nucleicos. 0 uso de técnicas utilizando ouro para detecção de App foi primeiramente descrito no ano de 2009, porém, o diagnóstico se baseava em detecção por fluorescência de anticorpo específicoí para a toxina $A p x I V$, com sensibilidade de 87,5\% e especificidade de 92,9\% (Sheng et al. 2009).

Usando-se a detecção do DNA genômico não amplificado, extraído diretamente do pulmão de suínos com e sem sinais clínicos o teste apresentou sensibilidade de 93,8\% e especificidade $84,6 \%$, sendo o valor kappa 0,684 demons- trando boa concordância. No grupo dos animais sem lesão macroscópica de pneumonia alcançou-se a sensibilidade de $100 \%$, entretanto a especificidade foi inferior a $80 \%$ e o teste kappa 0,767 indicando ótima concordância entre os testes de PCR e AuNP. A concordância entre os testes nos animais com lesão foi de 0,590 , sendo considerada boa. Os valores de sensibilidade e especificidade foram de $87,5 \%$ e $86,7 \%$, respectivamente. A utilização de DNA não amplificado pode gerar interferências nos testes moleculares, porém as reações cruzadas são menos frequentes do que nos testes sorológicos. Apesar das semelhanças genéticas entre os microrganismos que causam as doenças do complexo respiratório, pertencentes à família Pasteurellaceae, entre eles: App, Haemophilus parasuis e Pasteurella multocida (Hansen et al. 2010, Fablet et al. 2012) e ainda os microrganismos Mycoplasma hyopneumoniae e Streptococcus suis, a escolha dos oligonucleotídeos e dos genes alvos para os testes pode diminuir essas reações cruzadas.

A maior parte das técnicas moleculares e sorológicas exige algum grau de tecnificação por parte do local de realização e mão de obra capacitada, entretanto a técnica descrita neste trabalho pode ser aplicável em locais com menor infraestrutura, onde o uso de termociclador pode ser substituído por equipamentos mais simples e mais baratos, capazes de oscilar a temperatura como o banho-maria. A preparação das nanopartículas deve ser realizada em laboratório, entretanto apenas um agitador magnético com aquecimento se faz necessário. A solução estoque se mantém estável a $4^{\circ} \mathrm{C}$ em geladeiras convencionais, por tempo indeterminado e a solução de uso pode ser mantida em temperatura ambiente em torno de três meses, observando-se nesse tempo apenas a precipitação do soluto que inviabiliza seu uso. A campo, a utilização desta técnica representaria a possibilidade de detectar animais doentes com mais agilidade, pois o uso de kits comerciais de extração de DNA são facilmente obtidos, com custos variados, e de fácil manuseio, permitindo inibir a disseminação do agente, já que ocorre de forma rápida por aerossóis. $0 \mathrm{App}$ é um importante microrganismo em doenças respiratórias de suínos, de cultivo fastidioso e oneroso. A técnica de PCR tem sido bastante utilizada no diagnóstico deste agente, porém, a técnica de AuNP permite a detecção do mesmo sem amplificação prévia do DNA, o que permite uma detecção rápida com custo reduzido.

Agradecimentos.- À Coordenação de Aperfeiçoamento de Pessoal de Nível Superior (CAPES), pela concessão da bolsa de mestrado e à Fundação de Amparo à Pesquisa do Estado de Mato Grosso (Fapemat).

\section{REFERÊNCIAS}

Andreadou M., Liandris E., Gazouli M., Taka S., Antoniou M., Theodoropoulos G., Tachtsidis I., Goutas N., Vlachodimitropoulos D., Kasampalidis I. \& Ikonomopoulos J. 2014. A novel non-amplification assay for the detection of Leishmania spp. in clinical samples using gold nanoparticles. J. Microbiol. Methods 96:56-61.

Angen O., Oliveira S., Ahrens P., Svensmark B. \& Leser T.D. 2007. Development of an improved species specific PCR test for detection of Haemophilus parasuis. Vet. Microbiol. 119(2/4):266-276.

Bakthavathsalam P., Rajendran V.K. \& Mohammed J.A.B. 2012. A direct detection of Escherichia coli genomic DNA using gold nanoprobes. J. Nanobiotechnol. 10(8):1-10. 
Baptista P.V., Koziol-Montewka M., Paluch-Oles J., Doria G. \& Franco R. 2006. Gold-nanoparticle-probe-based assay for rapid and direct detection of Mycobacterium tuberculosis DNA in clinical samples. Clin. Chem. 52:1433-1434.

Bossé J.T., Janson H., Sheehan B.J., Beddek A.J., Rycroft A.N., Kroll J.S. \& Langford P.R. 2002. Actinobacillus pleuropneumoniae: pathobiology and pathogenesis of infection. Microbes Infect. 4(2):225-235.

Carter J., Velmurugan B., Cheryl K., Tresa F. \& Malcolm F. 2013. A novel dengue virus detection method that couples DNAzyme and gold nanoparticle approaches. Virology J. 10(201):1-15.

Chan W.S., Tang B.S., Boost M.V., Chow C. \& Leung P.H. 2014. Detection of methicillin-resistant Staphylococcus aureus using a gold nanoparticlebased colourimetric polymerase chain reaction assay. Biosens. Bioelectron. 53:105-111.

Chiers K., De Waele T., Pasmans F., Ducatelle R. \& Haesebrouck F. 2010. Virulence factors of Actinobacillus pleuropneumoniae involved in colonization, persistence and induction of lesions in its porcine host. Vet. Res. 41(65):1-19.

Coelho A.C., Vieira-Brito F.J., Vieira-Brito M.G. \& Rodrigues J. 2004. Swine pleuropneumonia due to Actinobacillus pleuropneumoniae: diagnosis and strategies of control. Revta Port. Ciênc. Vet. 99(552):193-198.

Eamens G.J., Gonsalves J.R., Whittington A.M. \& Turner B. 2012a. Evaluation of serovar-independent ELISA antigens of Actinobacillus pleuropneumoniae in pigs following vaccination or experimental challenge with respiratory pathogens and natural A. pleuropneumoniae serovar 1 challenge. Aust. Vet. J. 90(12):490-498.

Eamens G.J., Gonsalves J.R., Whittington A.M. \& Turner B. 2012b. Evaluation of serovar-independent ELISA antigens of Actinobacillus pleuropneumoniae in pigs, following experimental challenge with A. pleuropneumoniae, Mycoplasma hyopneumoniae and Pasteurella multocida. Aust. Vet. J. 90(6):225-234.

Fablet C., Marois C., Dorenlor V., Eono F., Eveno E., Jolly J.P., Le Devendec L., Kobisch M., Madec F. \& Rose N. 2012. Bacterial pathogens associated with lung lesions in slaughter pigs from 125 herds. Res. Vet. Sci. 93(2):627-630.

Fox, J. 2005. The R Comander: a basic statistics graphical user interface to R. J. Stat. Softw. 14(9):1-42

Gimenez-Lirola L.G., Jiang Y.H., Sun D., Hoang H., Yoon K.J., Halbur P.G., Opriessnig T. \& Litwin V.M. 2014. Simultaneous Detection of Antibodies against Apx Toxins ApxI, ApxII, ApxIII, and ApxIV in Pigs with Known and Unknown Actinobacillus pleuropneumoniae Exposure Using a Multiplexing Liquid Array Platform. Clin. Vaccine Immunol. 21(1):85-95.

Grabar K.C., Freeman R.G., Hommer M.B. \& Natan M.J. 1995. Preparation and characterization of Au colloid Monolayers. Anal. Chem. 67(4):735743.

Hansen M.S., Pors S.E., Jensen H.E., Bille-Hansen V., Bisgaard M., Flachs E.M. \& Nielsen O.L. 2010. An investigation of the pathology and pathogens associated with porcine respiratory disease complex in Denmark. J. Comp. Pathol. 143(2/3):120-131.

Hricinova M., Holoda E., Mudronova D. \& Ondrasovicova S. 2010. Multiplex PCR assay for detection of Actinobacillus pleuropneumoniae, Pasteurella multocida and Haemophilus parasuis in lungs of pigs from a slaughterhouse. Folia Microbiol., Praha, 55(6):635-640.

Hussain M.M., Samir T.M. \& Azzazy H.M. 2013. Unmodified gold nanoparticles for direct and rapid detection of Mycobacterium tuberculosis complex. Clin. Biochem. 46(7/8):633-637.

Instituto Brasileiro de Geografia e Estatística 2013. Estatística da Produção Pecuária, junho de 2013. , Indicadores IBGE. Disponível em <http:// www.ibge.gov.br/home/estatistica/indicadores/agropecuaria/producaoagropecuaria/abate-leite-couro-ovos_201301_publ_completa.pdf> Acesso em dezembro de 2013.

Klein C.S., Piffer I.A., Silva S.C., Schrank A., Favero M.B. \& Schrank I.S. 2003.
Detection of Actinobacillus pleuropneumoniae by PCR on field strains from healthy and diseased pigs. Curr. Microbiol. 46(6):443-447.

Liandris E., Gazouli M., Andreadou M., Comor M., Abazovic N., Sechi L.A. \& Ikonomopoulos J. 2009. Direct detection of unamplified DNA from pathogenic mycobacteria using DNA-derivatized gold nanoparticles. J. Microbiol. Methods 78(3):260-264.

Machado H.G., Piffer I.A., Guidoni A.L., Klein C. \& Gil-Turnes C. 2001. Avaliação de testes de ELISA para o diagnóstico sorológico de infecções pelos sorotipos 3, 5 e 7 de Actinobacillus pleuropneumoniae em suínos. Arq. Bras. Med. Vet. Zootec. 53:513-522.

Melo Jr, Alves M., Santos L.S.S., Gonçalves M.C. \& Nogueira A.F. 2012. Preparação de nanopartículas de prata e ouro: um método simples para a introdução da nanociência em laboratório de ensino. Quim. Nova 35:1872-1878.

Nossier A.I., Eissa S., Ismail M.F., Hamdy M.A. \& Azzazy H.M. 2014. Direct detection of hyaluronidase in urine using cationic gold nanoparticles: A potential diagnostic test for bladder cancer. Biosens. Bioelectron. 54:714.

Opriessnig T., Gimenez-Lirola L.G. \& Halbur P.G. 2011. Polymicrobial respiratory disease in pigs. Anim. Health Res. Rev. 12 (2):133-148.

R Core Team 2011. R: a language and environment for statistical computing. R Foundation for Statistical Computing, Vienna, Austria. URL <http://www.R-project.org/>

Rosa J.M.A., Almeida A.B.P.F., Tavares R.C., Brandão L.N.S., Pitchenin L.C., Rocha I.S.M., Sousa V.R.F., Dutra V. \& Nakazato L. 2013. Diagnóstico molecular da leishmaniose visceral canina através da técnica de sonda de nanopartículas de ouro (AuNPprobes). Semina, Ciênc. Agrárias 34(6:2):3777-3786.

Rossi C.C., Pereira M.F., Langford P.R. \& Bazzolli D.M. 2013. A BOX-SCAR fragment for the identification of Actinobacillus pleuropneumoniae. FEMS Microbiol. Lett. 353:32-37.

Sambrook J. \& Russel D.W. 2004. Molecular cloning: a laboratory manua. $3^{\text {rd }}$ ed. Cold Spring Harbor Laboratory Press, New York, p.5.65-5.67.

Schaller A., Djordjevic S.P., Eamens G.J., Forbes W.A., Kuhn R., Kuhnert P., Gottschalk M., Nicolet J. \& Frey J. 2001. Identification and detection of Actinobacillus pleuropneumoniae by PCR based on the gene apxIVA. Vet Microbiol. 79(1):47-62.

Sheng Z., Han H., Hu D., Liang J., He Q., Jin M., Zhou R. \& Chen H. 2009. Quantum dots-gold(III)-based indirect fluorescence immunoassay for high-throughput screening of APP. Chem. Commun., Cambridge, 18:2559-2561.

Shin M.K., . Kang M.L., Cha S.B., Lee W.J., Sung J.H. \& Yoo H.S. 2011. An immunosorbent assay based on the recombinant ApxIa, ApxIIa, and ApxIIIa toxins of Actinobacillus pleuropneumoniae and its application to field sera. J. Vet. Diagn. Invest. 23(4):736-742.

Souza K.K., Klein C.S., Kich J.D., Coldebella A. \& Alberton G.C. 2008. Reação em Cadeia da Polimerase (PCR) baseada no gene cpx para detecção de Actinobacillus pleuropneumoniae em suínos natural e experimentalmente infectados. Ciência Rural 38:1954-1960.

Townsend K.M., Boyce J.D., Chung J.Y., Frost A.J. \& Adler B. 2001. Genetic organization of Pasteurella multocida cap Loci and development of a multiplex capsular PCR typing system. J. Clin. Microbiol. 39(3):924-929.

Tremblay Y.D., Levesque C., Segers R.P. \& Jacques M. 2013. Method to grow Actinobacillus pleuropneumoniae biofilm on a biotic surface. BMC Vet. Res. 9(213):1-7.

Xiao G., Cao S., Duan L., Wen X., Ma X. \& Chen H. 2006. Identification and detection of Actinobacillus pleuropneumoniae in infected and subclinically infected pigs by Multiplex PCR based on the genes ApxIVA and OmlA. Agr. Sci. China 5(2):146-154.

Xie F., Zhang Y., Li G., Zhou L., Liu S. \& Wang C. 2013. The ClpP protease is required for the stress tolerance and biofilm formation in Actinobacillus pleuropneumoniae. PLoS One 8(1):e53600. 